\title{
A CORRELATION-BASED OPTICAL FLOWMETER FOR ENCLOSED FLOWS
}

\author{
N. Zhang, J. S. Dvorak, Y. Zhang
}

\begin{abstract}
A low-cost flowmeter would be very useful in a wide variety of monitoring situations. This article discusses the development of such a flowmeter based on optical components and its testing with water in an enclosed flow system. The sensor consisted of two sets of LEDs and phototransistors spaced $4 \mathrm{~cm}$ apart, monitoring the optical properties of the fluid at upstream and downstream locations, respectively. A small amount of dye was injected into the flow, which caused a change in the optical properties of the fluid at both locations. The time required for this change to move from the upstream to the downstream locations was determined using the biased estimate of the cross-covariance between the upstream and downstream signals. The velocity was then calculated using this time difference and the known distance between the locations. Tests were conducted at fluid velocities from 0.125 to $4.5 \mathrm{~m} \mathrm{~s}^{-1}$, and separate results were calculated using phototransistors located $45^{\circ}$ and $180^{\circ}$ from the LEDs. The mean percent error was between $5 \%$ and $0 \%$ for individual measurements using the $180^{\circ}$ phototransistors at velocities from 0.5 to $4.5 \mathrm{~m} \mathrm{~s}^{-1}$ and between $2 \%$ and $-8 \%$ for measurements using the $45^{\circ}$ phototransistors in the same velocity range. Error increased when the velocity was reduced to $0.5 \mathrm{~m} \mathrm{~s}^{-1}$ and was greater than $20 \%$ at $0.125 \mathrm{~m} \mathrm{~s}^{-1}$ for both sets of phototransistors. A regression model was developed to correct the velocity estimate. This regression model was validated by conducting an independent test of the sensor under the same conditions. After using the regression model for calibration, errors in the validation set were between $9.1 \%$ and $5 \%$ for the $180^{\circ}$ phototransistors and between $10.5 \%$ and $-3.6 \%$ for the $45^{\circ}$ phototransistors for the entire velocity range tested $\left(0.125\right.$ to $\left.4.5 \mathrm{~m} \mathrm{~s}^{-1}\right)$. Finally, the cross-correlation coefficient for each measurement was calculated to determine the degree of similarity between the signals recorded by the phototransistors at the upstream and downstream locations. The cross-correlation coefficient was higher at lower velocities and higher for measurements using the $180^{\circ}$ phototransistors.
\end{abstract}

Keywords. Cross-correlation, Flowmeters, Optical, Sensor, Velocity.

$\mathrm{A}$ ccurate determination of fluid velocity is important in numerous areas, from irrigation to environmental monitoring to municipal water distribution. Given the wide variety of applications, a large number of methods for determining flow velocity have been developed. In general, each method for determining fluid flow velocity involves a tradeoff between cost/complexity, accuracy, robustness, and the effect on the flow being monitored. Many traditional velocity sensors operate through mechanical interaction with the fluid flow. Examples of this kind of sensor include thin-plate orifices, nozzles, pitot tubes, vortex meters, Thomas or thermal meters, and various rotating mechanical devices. Thin-plate orifice designs can be built with accuracies of $1 \%$ to $5 \%$, while nozzle and Venturi nozzle systems can achieve accuracies of $0.5 \%$ to $2 \%$ (ASHRAE, 2009). However, all of

Submitted for review in November 2012 as manuscript number IET 10052; approved for publication by the Information \& Electrical Technologies Division of ASABE in November 2013.

The authors are Naiqian Zhang, ASABE Fellow, Professor, Department of Biological and Agricultural Engineering, Kansas State University, Manhattan, Kansas, Joseph S. Dvorak, ASABE Member, Assistant Professor, Department of Biosystems and Agricultural Engineering, University of Kentucky, Lexington, Kentucky, and Yali Zhang, Lecturer, South China Agricultural University, Guangzhou, China Corresponding author: Joseph Dvorak, 128 C.E. Barnhart Building, University of Kentucky, Lexington, KY 40546-0276; phone: 859-2573000, ext.107; e-mail: joe.dvorak@uky.edu. these designs are highly dependent on the geometry of the sensor and are thus very susceptible to sediment or other deposits. They also cause a loss of pressure. Velocity measurements based on pitot tubes and Thomas or thermal meters only intrude into a small portion of the flow and thus have less effect on the flow. However, the durability of these sensors is an issue, which prevents their use in fluids containing particles that could either directly damage the device or change the alignment of the sensor (Blake, 1983; White, 2003). Vortex meters can have fewer problems with frailty, as the bluff body used to generate vortexes in the flow can be more robust (White, 2003). However, the bluff body must still intrude into the flow, which could be detrimental in some measurement situations. Finally, many commonly used flowmeters are based on rotating mechanical parts, such as turbines, propellers, or anemometers. While these sensors include a wide variety of designs with accuracies of $0.25 \%$ to $2 \%$ (ASHRAE, 2009; White, 2003), they require calibration, and care must be taken to ensure that debris in the flow does not damage the rotors (Dodge, 2001; Upp and LaNasa, 2002). While many of these types of devices have been tested and used for many years, the requirement for mechanical interaction with the flow represents a major limitation of these devices.

More recently, sensors that do not rely on direct mechanical interaction for measuring fluid flow have been developed. These include electromagnetic flowmeters, ul- 
trasonic flowmeters, laser Doppler anemometers, and particle image velocimetry. Electromagnetic flowmeters are limited by the fact that the fluid must be conductive (Shercliff, 1962). In low conductive fluids like fresh water, the operation becomes more difficult (White, 2003). Ultrasonic flowmeters can be based on the transit time of ultrasonic waves or on the Doppler effect. Ultrasonic devices called acoustic Doppler velocimeters and acoustic Doppler current profilers have seen widespread usage in open-channel measurements (Muste et al., 2007). Although ultrasonic devices appear very promising for being less intrusive to fluid flow, they are limited by high cost, which necessitates their installation in areas where they will not be damaged (Levesque and Oberg, 2012). Laser Doppler anemometers and particle image velocimetry are both mainly limited to laboratory applications because of the high cost of the equipment and design requirements. However, they can be extremely useful in those applications. Laser Doppler anemometers can achieve $0.1 \%$ accuracy at velocities from $10 \mu \mathrm{m} \mathrm{s}^{-1}$ to $1 \mathrm{~km} \mathrm{~s}^{-1}$ (Adrian, 1983), and particle image velocimetry provides a method of capturing the entire flow field in a fluid in either two or three dimensions (Elsinga et al., 2006). Particle image velocimetry operates by introducing seeding particles in the flow stream. Like the sensor presented in this article, the velocities of various particles trapped in the fluid flow are determined using the statistical method of cross-correlation (Raffel et al., 2007). While all of these methods allow fluid flow measurements without direct mechanical contact, applications are limited by the cost of the systems.

One particularly challenging area for fluid velocity sensors is to monitor water flows in natural environments. The water flowing in these systems often contains sediment and other debris that the sensor must be able to tolerate. The optical sensor developed in this study attempts to provide a low-cost, robust method of velocity measurement for remote monitoring of natural water systems. The sensor discussed in this article was a part of a larger system that was designed to monitor both soil sediment concentration and velocity in open-channel flows. In this intended application, the closedtube sensor structure shown in this article would be changed to a U-shape with one side open to the open-channel flow. As a first step in developing the velocity measurement, the sensor was tested in enclosed flow conditions, and the results of this testing and development are presented in this article. The primary objective of the project presented in this article was to determine the ability of a correlation-based optical sensor to measure the velocity of enclosed water flows in the range of 0.125 to $4.5 \mathrm{~m} \mathrm{~s}^{-1}$. This range was selected because it covers most of the velocity range experienced in natural openchannel flows. A secondary objective was to establish a correction method to account for any discrepancies between the actual velocity and the estimate from the sensor. After completing this development effort, the final goal is a sensor that provides simultaneous, discrete measurements of soil sediment concentration and water velocity that could be incorporated into a standard stream gauging station for long-term monitoring of stream conditions. This article describes only the velocity measurement function of the sensor.

\section{MeTHODS}

\section{SENSOR STRUCTURE}

The sensor design is a continuation of work on a combined soil sediment and fluid velocity sensor developed by Stoll (2004) and Zhang (2009). The velocity component was based on an earlier project by Eam-o-pas et al. (1997) that used similar optical components and mathematical techniques to determine the velocity of grain, straw, and glass beads (Eamopas et al., 1994). Chang et al. (1986) provided an even earlier implementation of this type of technique in determining the velocity of grain. Figure 1 depicts the structure of the sensor. The sensor was constructed using a solid plastic body into which were mounted LEDs and phototransistors. This solid sensor body was connected to a piece of standard polyvinyl chloride (PVC) pipe with an internal diameter of $1.91 \mathrm{~cm} \mathrm{(3/4} \mathrm{in.,} \mathrm{schedule} 80)$. There are two sets of LEDs and phototransistors (labeled upstream and downstream in fig. 1a). In each set, light emitted by an LED is detected by two corresponding phototransistors. As shown in figure $1 \mathrm{~b}$, the phototransistors were located at a $45^{\circ}$ angle from the LED (labeled $45^{\circ} \mathrm{PT}$ ) and directly across from the LED (labeled $180^{\circ} \mathrm{PT}$ ) to measure backscattered and transmitted lights from the LED, respectively. This basic structure of an LED and photodetector pair has been used in sensors for a wide variety of applications. For example, Vondricka and Lammers (2009) used a single LED and photodiode pair to evaluate mixture homogeneity in direct-injection sprayer applications.

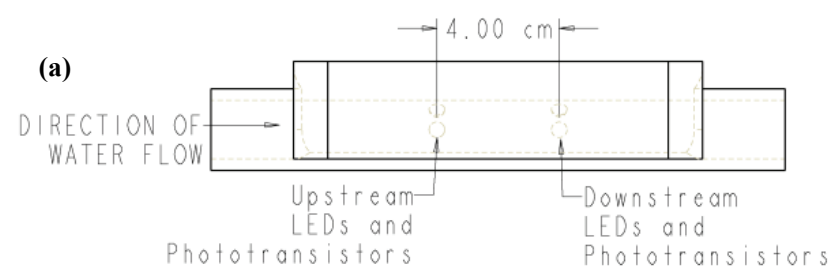

(b)

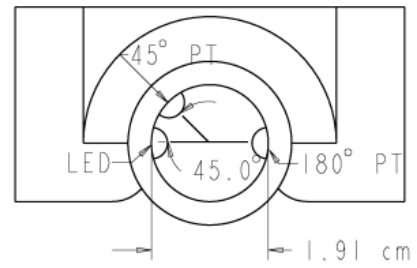

(c)

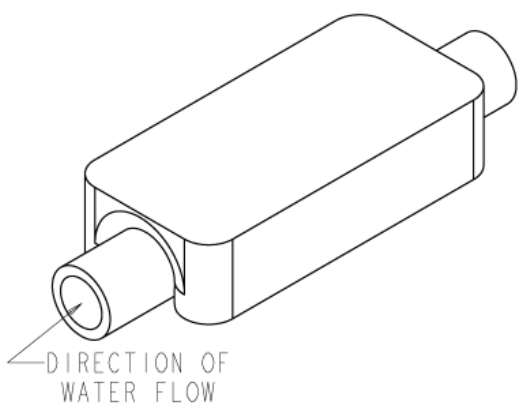

Figure 1. Internal structure of sensor: (a) side view showing the two sets of LEDs and phototransistors, (b) end view showing the placements of LED and phototransistors within each set, and (c) a threedimensional view of the sensor. 
Although the sensor contained orange, blue-green, and infrared LEDs for sediment monitoring, only the orange LEDs and the corresponding phototransistors were used for velocity measurements. The orange LEDs were model SSL-LX5093SOC (Lumex, Carol Stream, Ill.), which had a maximum light output at a wavelength of $610 \mathrm{~nm}$. The phototransistors used in the sensor were model SFH314 (Osram Opto Semiconductors GmbH, Regensburg, Germany), which had a wide response range from 460 to $1080 \mathrm{~nm}$ with the peak response at $850 \mathrm{~nm}$. Figure 2 shows the basic schematic for this system, with the LED control on the left half of the diagram and the phototransistor signal conditioning on the right. The current through both LEDs was controlled by a single $100 \Omega$ resistor. Although individual resistors for each LED are generally preferred, this simpler design was used since both LEDs were always turned on simultaneously. The phototransistors produced an electric current based on the light received, which was converted into a voltage using the resistors labeled R_CAL in the schematic. Changing the values of these resistors allowed the sensor to be calibrated, to adjust the sensitivity to account for manufacturing differences or installation in water with different concentrations of sediment. While the crosscorrelation function used to determine velocity was relatively unaffected by differences in sensitivity because of its statistical nature, this calibration was important for soil sediment concentration measurements. A standard voltage- follower circuit was then used to provide low output impedance for connection to an analog-to-digital converter.

A small amount of dye was injected into the water upstream from the sensor to create the change in the optical properties of the flow. As the water carrying the dye flowed through the sensor, the dye absorbed some of the light from the LED. This caused less light to reach the phototransistors and, hence, a decrease in the signal level. This decrease in signal level occurred in the upstream signals first and then in the downstream signals. The average velocity of the water was calculated by determining the time difference between the signal changes in the upstream and downstream signals. The dye used in this experiment was erioglaucine disodium salt (Sigma-Aldrich, St. Louis, Mo.) at a concentration of $5 \mathrm{~g} \mathrm{~L}^{-1}$ of water. Erioglaucine disodium salt has the chemical formula $\mathrm{C}_{37} \mathrm{H}_{34} \mathrm{Na}_{2} \mathrm{~N}_{2} \mathrm{O}_{9} \mathrm{~S}_{3}$ and is also known as Acid Blue 9, FD\&C Blue No. 1, and Brilliant Blue FCF, among other synonyms. This dye has been used widely in water infiltration studies (Bundt et al., 2001; Flury and Flühler, 1995; Motz et al., 2012; Vryzas et al., 2012). Flury and Flühler (1994) conducted a toxicological review of this dye and noted its use in food coloring, toilet bowl cleaners, and to improve the aesthetics of golf water hazards. They concluded that the dye was safe for use in soil water infiltration studies, where it would be used at concentrations between 3 to $5 \mathrm{~g} \mathrm{~L}^{-1}$. However, they also noted the toxicity to aquatic creatures and advised ensuring

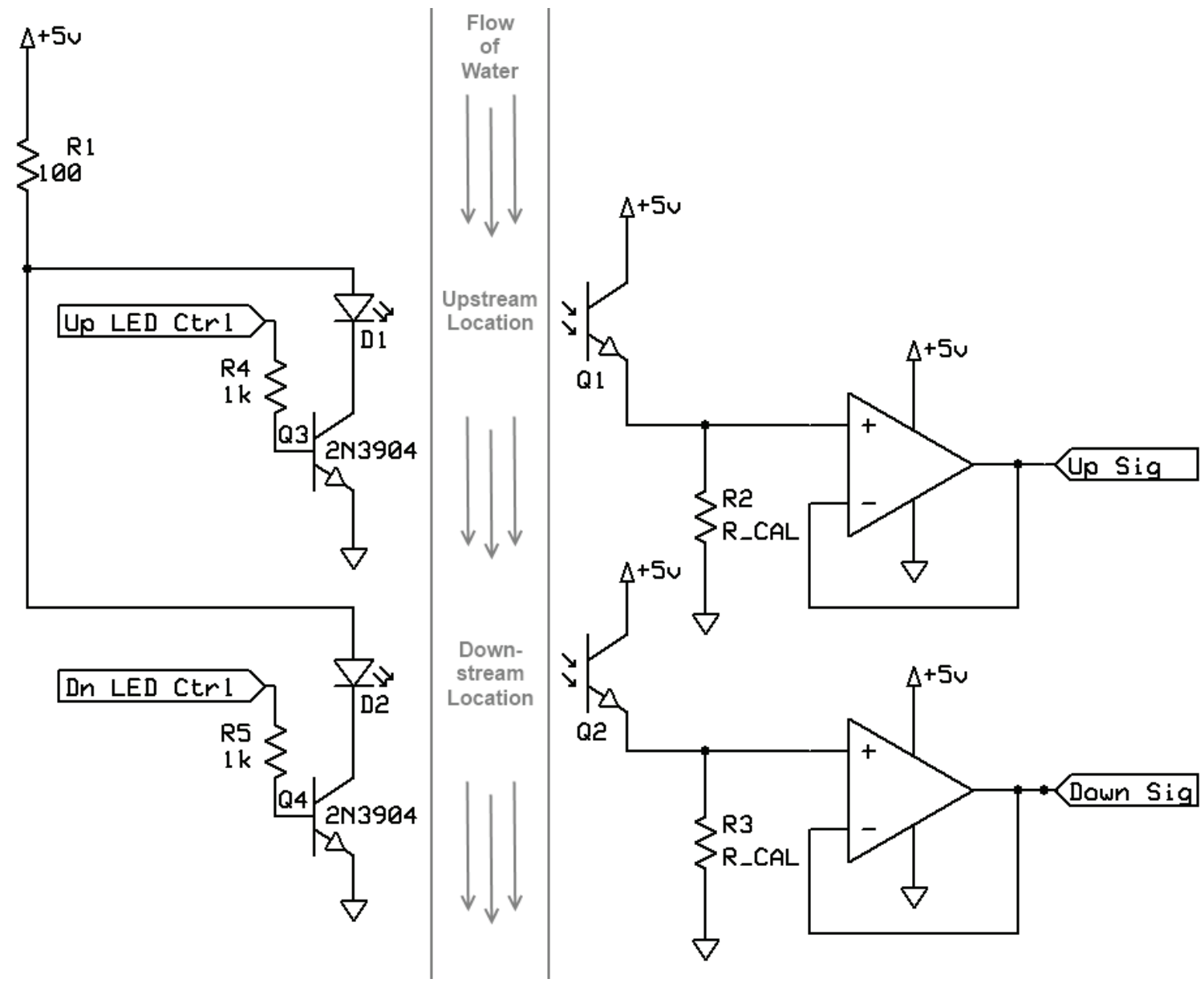

Figure 2. Sensor control and signal conditioning schematic. 
that final concentrations in water are below $1 \mathrm{mg} \mathrm{L}^{-1}$. In this study, each velocity measurement involved the injection of only $375 \mu \mathrm{L}$ of dye solution, which contained $1.875 \mathrm{mg}$ of erioglaucine disodium salt. Thus, a single injection required dilution in just $1.875 \mathrm{~L}$ to remain below the suggested $1 \mathrm{mg} \mathrm{L}^{-1}$ level. Erioglaucine disodium salt has a maximum absorption of visible light at a wavelength of $625 \mathrm{~nm}$, making it especially suitable to blocking the $610 \mathrm{~nm}$ light from the orange LEDs.

\section{VElocity CALCULATION}

The velocity is determined by finding the time delay for the dye to travel from the upstream phototransistors to the downstream phototransistors. This delay appears as the difference between the times when the dye changes the upstream and downstream signals, respectively. Time differences between signals are often determined using the cross-correlation between the signals (Bendat and Piersol, 1986), but because the signals produced by this sensor had non-zero means, the closely related cross-covariance was more appropriate to use (Bendat and Piersol, 1993):

$$
C_{x y}(\tau)=E\left[\left(x(t)-\mu_{x}\right)\left(y(t+\tau)-\mu_{y}\right)\right]
$$

where

$C_{x y}(\tau)=$ cross-covariance

$E[]=$ expected value

$x(t)$ and $y(t)=$ upstream and downstream signals, respectively $(\mathrm{V})$

$\tau=$ time delay (s)

$\mu_{x}=$ mean of $x(t)$

$\mu_{y}=$ mean of $y(t)$.

The cross-covariance of two signals is maximized at the time delay $(\tau)$ when the two signals closely match each other. For discrete signals, the cross-covariance can be estimated using biased or unbiased methods. The unbiased estimate of cross-covariance is:

$$
\hat{C}_{x y}(r T)=\frac{1}{N-r} \sum_{n=1}^{N-r}\left(x_{n}-\mu_{x}\right)\left(y_{n+r}-\mu_{y}\right)
$$

$\hat{C}_{x y}(r T)=$ discrete time estimate of cross-covariance

$r=$ number of samples by which the downstream signal is shifted (also called lag number)

$T=$ sampling interval (s)

$N=$ total number of samples.

The biased estimate of cross-covariance is:

$$
\hat{C}_{x y}(r T)=\frac{1}{N} \sum_{n=1}^{N-r}\left(x_{n}-\mu_{x}\right)\left(y_{n+r}-\mu_{y}\right)
$$

The cross-covariance calculated from the unbiased estimate was dependent not only on the degree to which the signals matched but also on the sample length of the signals and the time delay between the signals. Generally, the unbiased estimate tended to underestimate velocities because as the lag number $(r)$ increased, the denominator in equation 2 decreased, resulting in a higher cross-covariance estimate. Therefore, the biased estimate of cross-covariance was used in this study.

The cross-correlation coefficient (CCC) provides addition information about how closely the signals match. It can be calculated from the cross-covariance function (Bendat and Piersol, 1986):

$$
\rho_{x y}(\tau)=\frac{C_{x y}(\tau)}{\sigma_{x} \sigma_{y}}=\frac{C_{x y}(\tau)}{\sqrt{C_{x x}(0) C_{y y}(0)}}
$$

where

$$
\rho_{x y}(\tau)=\text { cross-correlation coefficient }
$$

$\sigma_{x}$ and $\sigma_{y}=$ standard deviations of $x(t)$ and $y(t)$, respectively.

Like the cross-covariance from which it is calculated, the CCC is a function of the time delay $(\tau)$ and is a scaled version of the cross-covariance. The cross-correlation coefficients range from -1 to 1 ; a CCC of 0 at a particular time delay $(\tau)$ indicates that the signals are uncorrelated at that time delay. As the CCC approaches 1, it indicates that the signals are closer matches. When it approaches -1 , it indicates that one signal is a closer match to the inverse of the other signal (Jenkins and Watts, 1968).

The time delay for the dye to travel from the upstream phototransistors to the downstream phototransistors was determined by finding the time delay when the crosscovariance function reached the maximum value. The CCC was also calculated at this same time delay as it provides a useful indication of how closely the signals matched. Closely matched signals indicate that the signal changes caused by the dye were clearly captured by both sets of phototransistors and that the shape and size of the dye in the flow was relatively unchanged between phototransistors. Thus, a high cross-correlation coefficient corresponds to a better operation of the sensor. Finally, the velocity is calculated by simply dividing the known $4 \mathrm{~cm}$ distance between the phototransistors by the time delay.

For sampled signals, the measured velocities have discrete values (eqs. 2 and 3). The quantization error associated with assigning the velocity to a discrete value decreases with higher sampling rates and lower velocities. For example, to limit the quantization error to less than $1 \%$ at a velocity of $4.5 \mathrm{~m} \mathrm{~s}^{-1}$, the sample rate must be at least $5,738 \mathrm{~Hz}$. The cross-correlation function is a statistical function and is widely used for its ability to determine the time difference between signals in the presence of random noise. With the cross-correlation function's robustness against random noise, the quantization error can be reduced by raising the sampling frequency, although higher sampling frequencies demand longer processing time and larger memory space. Memory requirements are also increased when measuring lower velocities because sampling must continue until the dye passes the sensor. Future embedded applications of this technology must carefully consider the acceptable tradeoffs between quantization error, memory requirements, processing time, and the range of velocities to be measured.

\section{EXPERIMENT SETUP}

The experimental setup is shown in figure 3. During the 


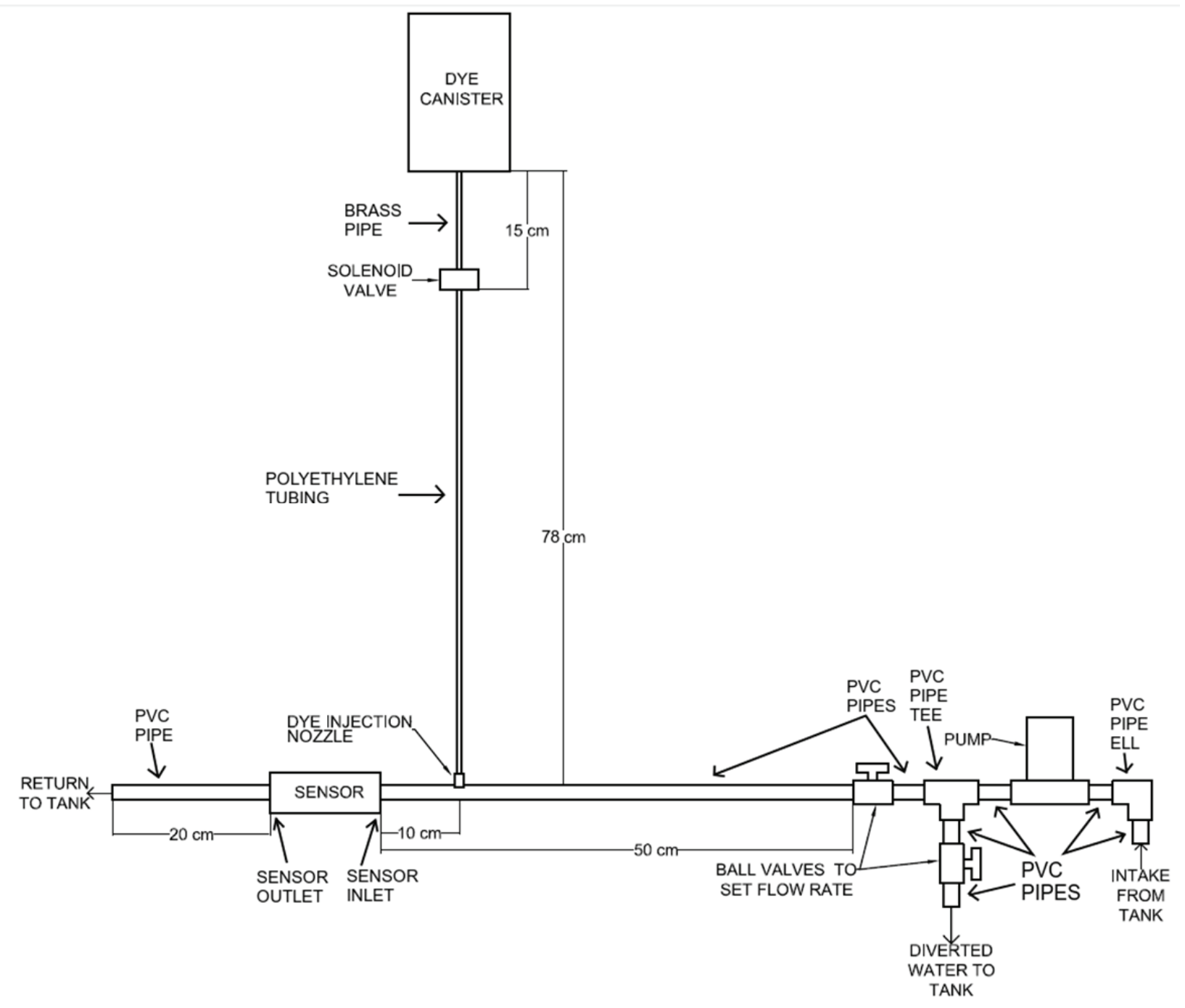

Figure 3. Experiment setup for the sensor in enclosed flow.

test, the sensor was attached to PVC pipes with the same $1.91 \mathrm{~cm}$ internal diameter (3/4 in., schedule 40$)$ as the sensor itself. A straight horizontal section of PVC pipe was maintained for $50 \mathrm{~cm}$ before the sensor inlet and for $20 \mathrm{~cm}$ after the sensor outlet. A $0.37 \mathrm{~kW}(1 / 2 \mathrm{hp})$ electric portable utility pump was used to maintain the water flow. Two PVC ball valves were used to direct the flow either through the sensor or back into the $378 \mathrm{~L}$ holding tank, which was large enough to ensure sufficient dye dilution before recirculation, given the small amount of dye injected in each measurement. Using these valves, the water velocity through the pipe could be adjusted from 0.125 to $4.5 \mathrm{~m} \mathrm{~s}^{-1}$. These valves were adjusted to produce an average velocity close to the nominal desired velocity. This was confirmed by measuring the actual water velocity by timing how long it took to fill a container of a known volume. During sample runs, the same volumetric flask test was used to record the actual average velocity during sensor tests, and this was the value used in all data analyses. The water used in the experiment was tap water at $20^{\circ} \mathrm{C}$ from the municipal water supply.

The dye was injected through a nozzle $1.6 \mathrm{~mm}$ in diameter into the pipe $10 \mathrm{~cm}$ before the sensor inlet. This injec- tion point was selected based on some preliminary testing. In an ideal situation, a very small amount of dye would be carried by the water as a single unchanging unit through the sensor, completely absorbing the light to be picked up by the phototransistors, and producing the exact same sharp, short, and distinct signal pulse in both sets of phototransistors. This requires as little mixing as possible between the dye and the water. However, too little mixing results in such a small packet of dye that it could completely miss the light path from the LED to the phototransistors. After several tests, this injection point was selected to minimize mixing while ensuring dye detection across the range of velocities tested. The distance between the sensor inlet and the first LED/phototransistor set was $4.7 \mathrm{~cm}$. Thus, the total distance between the dye injection point and the first LED/phototransistor set was $14.7 \mathrm{~cm}$. The dye container was $78 \mathrm{~cm}$ above the sensor, and this generated enough head pressure to ensure that the dye flowed through the nozzle into the pipe. A solenoid valve was used to control the flow of the dye. It was located $15 \mathrm{~cm}$ below the dye canister and was connected to the dye canister by brass pipe (9.2 mm i.d., $13.7 \mathrm{~mm}$ o.d., nominal $1 / 4$ in. pipe). The dye flowed from the solenoid valve (12 VDC solenoid, Lake 
Products, Inc., Park Rapids, Minn.) to the dye injection nozzle through polyethylene tubing with an internal diameter of $4.3 \mathrm{~mm}$ and an external diameter of $6.4 \mathrm{~mm}$. The dye was injected by turning on the solenoid valve for $15 \mathrm{~ms}$. With the solenoid's $10 \mathrm{~ms}$ time-to-open and $20 \mathrm{~ms}$ time-toclose, this $15 \mathrm{~ms}$ pulse to turn on the solenoid resulted in an injection of $375 \mu \mathrm{L}$ of dye. This $15 \mathrm{~ms}$ solenoid activation time was selected after a preliminary test, which indicated that this was the shortest duration pulse (and thus the lowest dye injection amount) at which the solenoid and the entire dye injection system responded consistently. Increases in the pulse duration only resulted in increased dye injection without appreciable increases in sensor performance.

The electronics of the sensor system were connected to a National Instruments PCI-6025E data acquisition board installed in a PC. A LabVIEW program on the PC controlled the injection of the dye and recorded the sensor output through this board. The outputs from the four phototransistors were simultaneously sampled and recorded at 50,000 samples per second. The signals were sampled for $1 \mathrm{~s}$ for water flow velocities of 0.75 to $4.5 \mathrm{~m} \mathrm{~s}^{-1}$, for $2 \mathrm{~s}$ for velocities of $0.25 \mathrm{~m} \mathrm{~s}^{-1}$ and $0.5 \mathrm{~m} \mathrm{~s}^{-1}$, and for $4 \mathrm{~s}$ for a water velocity of $0.125 \mathrm{~m} \mathrm{~s}^{-1}$. These lengths of time guaranteed that the dye flowed completely past the upstream and downstream LED/phototransistor sets before the sampling stopped.

Using the testing system, ten samples were recorded at each of the following velocities: $0.125,0.25,0.5,0.75,1$, $1.5,2,2.5,3,3.5,4$, and $4.5 \mathrm{~m} \mathrm{~s}^{-1}$. With the $20^{\circ} \mathrm{C}$ water used, the Reynolds numbers for the flows in these tests were above 9,000 at velocities above $0.5 \mathrm{~m} \mathrm{~s}^{-1}$, indicating that these flows were completely turbulent. At $0.25 \mathrm{~m} \mathrm{~s}^{-1}$, the Reynolds number was 4,766, and the flow was just barely in the turbulent region. At $0.125 \mathrm{~m} \mathrm{~s}^{-1}$, the Reynolds number was only 2,383 , and flow was transitional and almost in the laminar flow region. At each velocity, the samples from the phototransistors at $45^{\circ}$ and at $180^{\circ}$ were processed separately to create velocity estimates. The entire test with ten samples at each of the twelve different velocities was performed twice using the same test procedure.

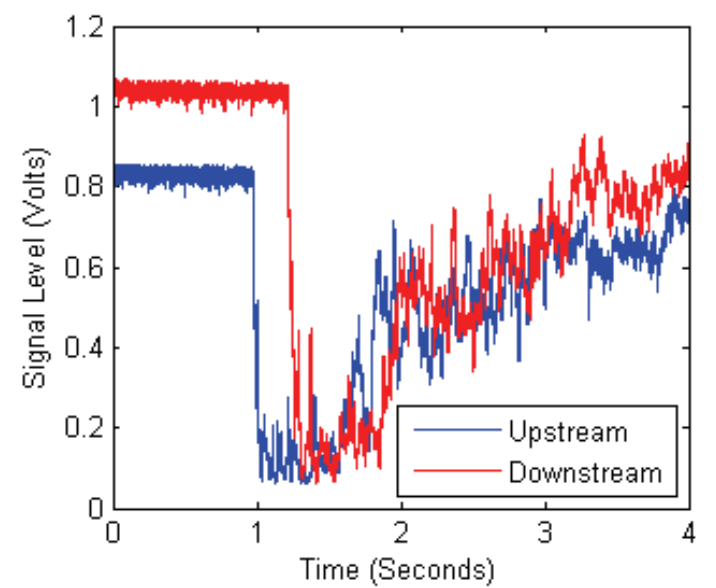

(a)
The results from the first test were used to create a regression model to calibrate the sensor. This model was then checked with data from the second test for validation. This testing was performed in a laboratory setting with tap water in enclosed-flow situations where the experimental conditions could be carefully controlled. The testing in this article does not address the environmental hazards expected with open-channel flows. However, follow-up testing was conducted in less ideal and controlled natural open channels to ascertain the sensor's ability to operate in adverse environmental situations. Results of the open-channel tests will be reported in another article.

\section{RESULTS AND DISCUSSION \\ SigNALS FROM THE PHOTOTRANSISTORS}

The signals recorded from the phototransistors $180^{\circ}$ from the LEDs at $0.125 \mathrm{~m} \mathrm{~s}^{-1}$ are shown in figure 4a. Figure $4 \mathrm{~b}$ shows the downstream signal shifted up to match the upstream signal using the time delay indicated by the crosscovariance estimate. Figure 5 is the same measurement at $0.125 \mathrm{~m} \mathrm{~s}^{-1}$ recorded by the phototransistors $45^{\circ}$ from the LEDs. The light transmitted directly from the LEDs to the phototransistors across the sensor is much stronger than the light backscattered from the clean water used in the experiment. Therefore, the signal levels from the $180^{\circ}$ phototransistors are much higher than those from the $45^{\circ}$ phototransistors. The effect of the dye is clearly visible in both measurements. In both cases, after shifting the downstream signal by the time delay estimated from the crosscovariance, the front edge of the downstream signal closely aligned with that of the upstream signal (figs. $4 \mathrm{~b}$ and $5 \mathrm{~b}$ ).

The signals from the $180^{\circ}$ and $45^{\circ}$ phototransistors recorded at a water velocity of $4.5 \mathrm{~m} \mathrm{~s}^{-1}$ are shown in figure 6 and figure 7 , respectively. The signal change caused by the dye was much less in these measurements. There was also more noise, represented by the random spikes in the signals. The cause of the increased noise was not determined, but at this velocity the water was travelling very quickly though the pipe, and bubbles could have been trapped in

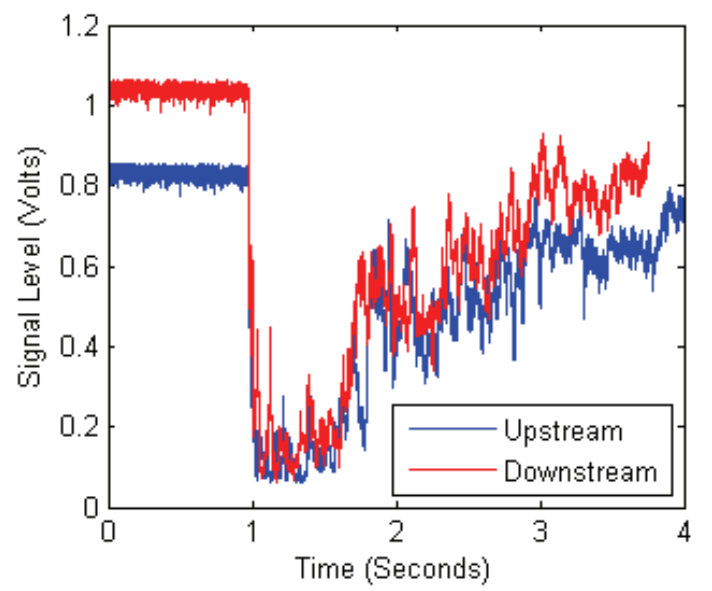

(b)

Figure 4. Signals from $180^{\circ}$ phototransistors with a water velocity of $0.125 \mathrm{~m} \mathrm{~s}^{-1}$ (a) as recorded and (b) shifted to align the signals as determined by the cross-correlation. 


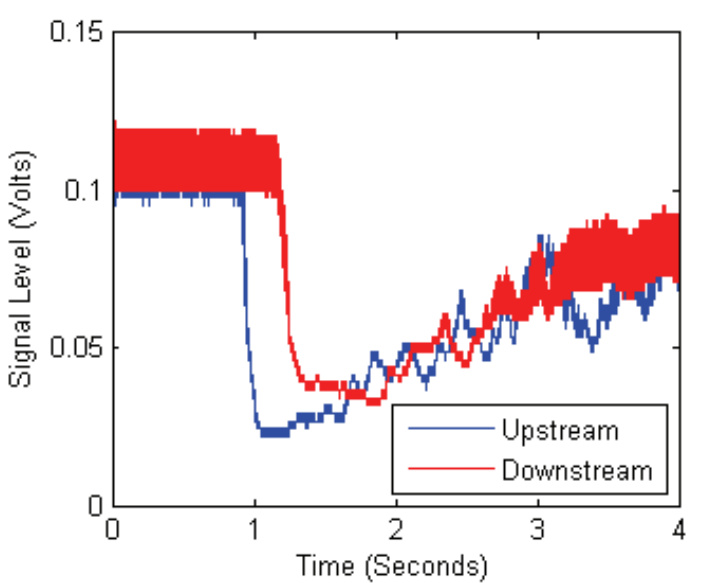

(a)

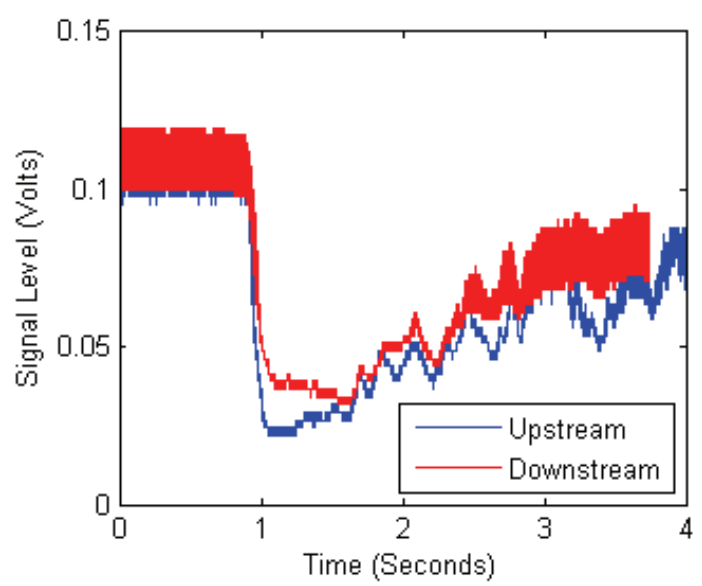

(b)

Figure 5. Signals from $45^{\circ}$ phototransistors with a water velocity of $0.125 \mathrm{~m} \mathrm{~s}^{-1}$ (a) as recorded and (b) shifted to align the signals as determined by the cross-correlation.

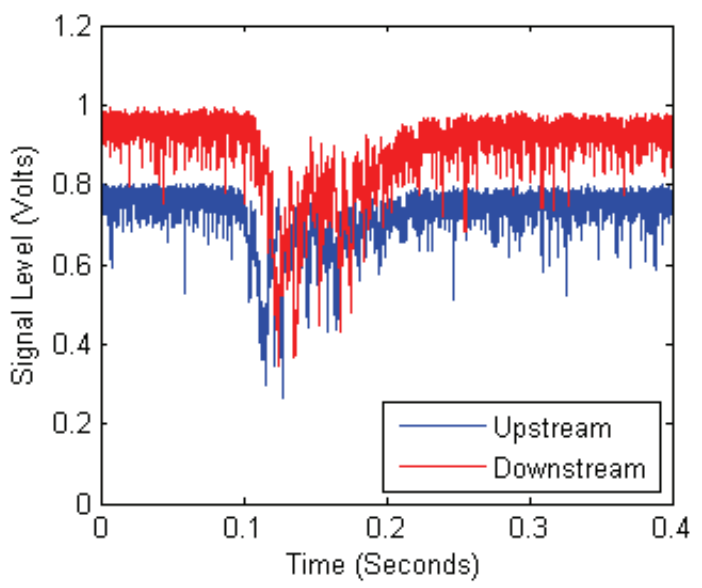

(a)

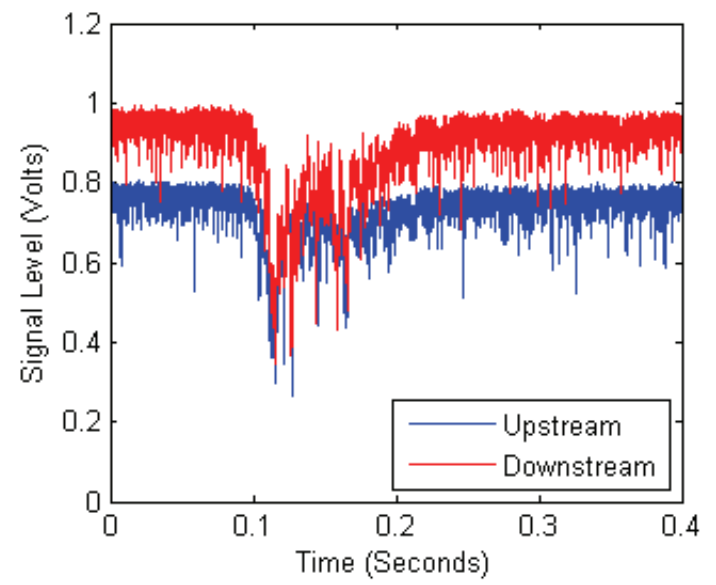

(b)

Figure 6. Signals (first $0.4 \mathrm{~s}$ ) from $180^{\circ}$ phototransistors with a water velocity of $4.5 \mathrm{~m} \mathrm{~s}^{-1}$ (a) as recorded and (b) shifted to align the signals as determined by the cross-correlation.

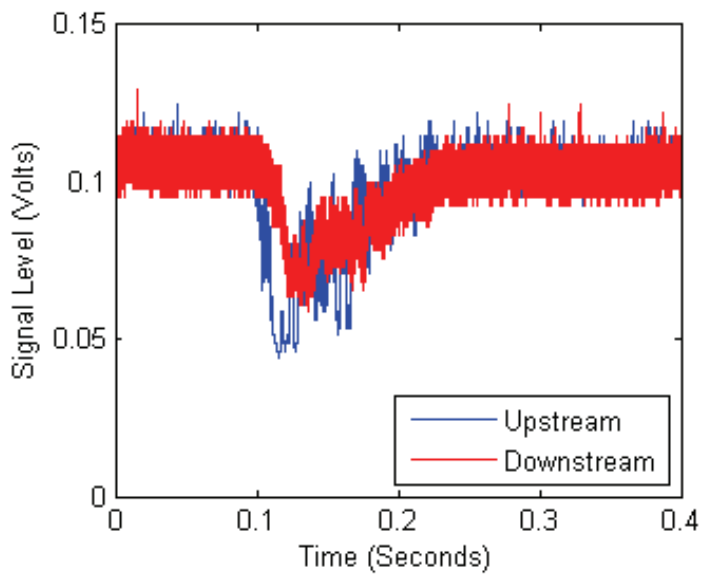

(a)

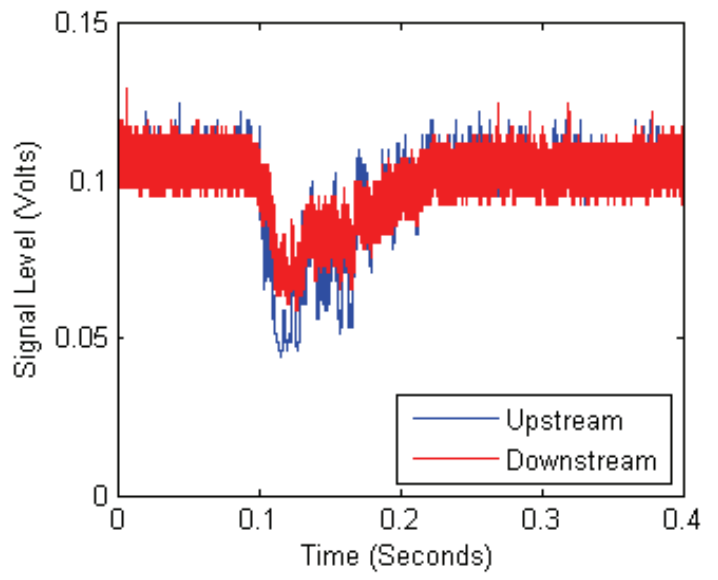

(b)

Figure 7. Signals (first $0.4 \mathrm{~s}$ ) from $45^{\circ}$ phototransistors with a water velocity of $4.5 \mathrm{~m} \mathrm{~s}^{-1}$ (a) as recorded and (b) shifted to align the signals as determined by the cross-correlation.

the flow. The shifting of the signals based on the crosscorrelation was much less, as there was less time delay between the signal spikes in the upstream and downstream signals caused by dye.

\section{TEST FOR CALIBRATION}

The velocity measured by the sensor using signals from the phototransistors $180^{\circ}$ from the LEDs is plotted against the true velocity of the water flow in figure 8 . This chart also shows the CCC of each measurement through the color and 


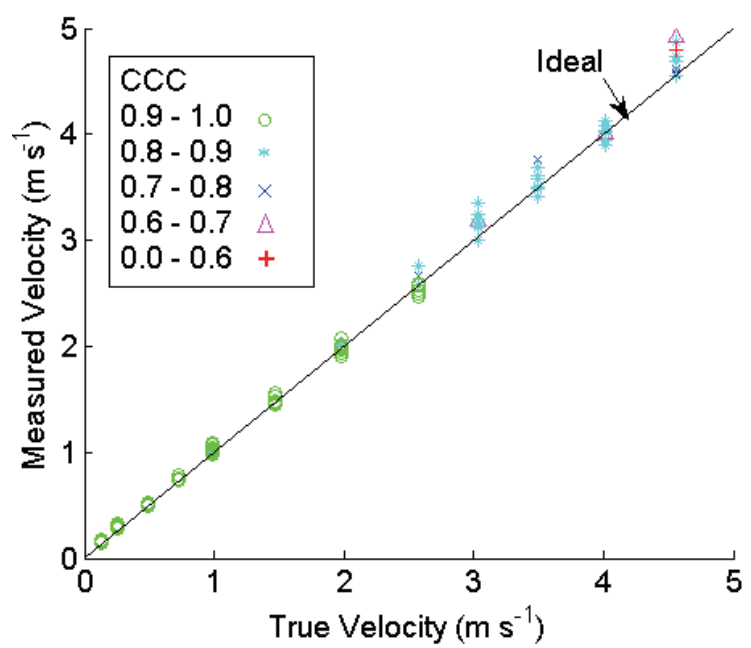

Figure 8. Measured velocity compared to true velocity and $\mathrm{CCC}$ of each measurement using the signals from the $180^{\circ}$ phototransistors in the calibration test.

symbol used to plot the data point. Figure 9 shows the same data using the signals from the phototransistors $45^{\circ}$ from the LEDs. The solid line in each figure shows the ideal case where the velocity measured by the sensor exactly matches the true velocity. In both sets of measurements, the CCC of the measurements was higher at lower velocities. In addition, at a given velocity, the measurements from the $180^{\circ}$ phototransistors had higher CCC than those from the $45^{\circ}$ phototransistors. Finally, the measurements using the $180^{\circ}$ phototransistors remained tightly bunched around the ideal measurement from low to high velocities. However, in the data from the $45^{\circ}$ phototransistors, the velocity was underestimated at higher velocities.

The CCC was used to determine the quality of the velocity measurements. Figure 10 shows the percentage of measurements at each velocity that had a CCC above 0.75 . Only these measurements were considered acceptable for further processing. Measurements with a CCC below 0.75 indicated that there were significant differences between the shapes of the upstream and downstream signals, which may indicate

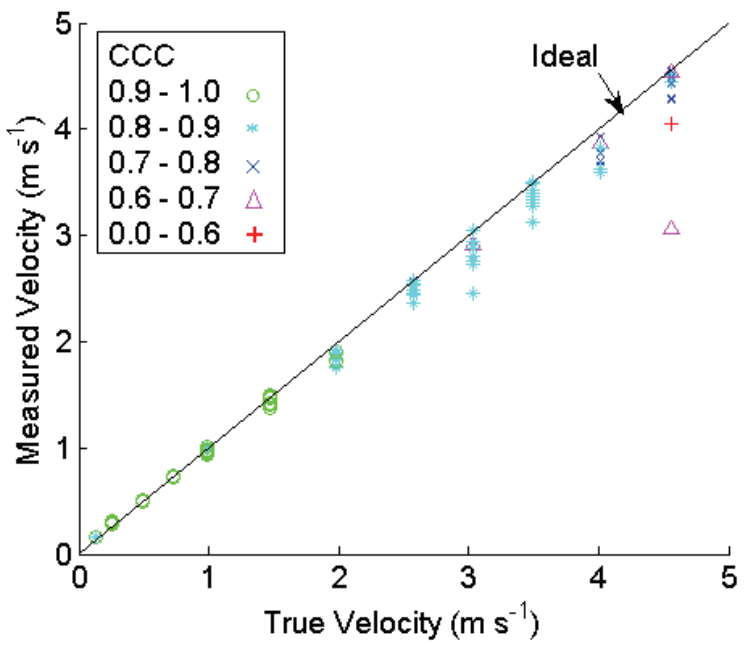

Figure 9. Measured velocity compared to true velocity and $\mathrm{CCC}$ of each measurement using the signals from the $45^{\circ}$ phototransistors in the calibration test.

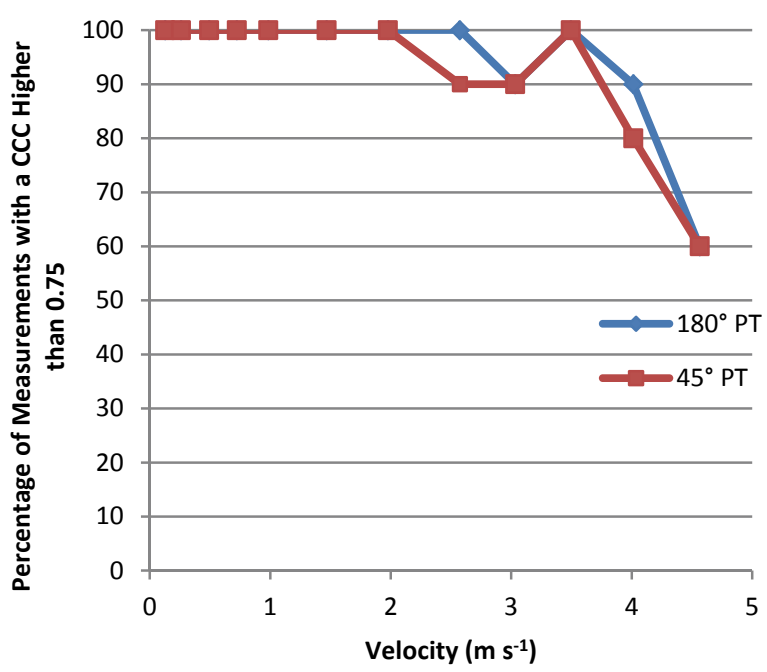

Figure 10. Percent of measurements with $\mathrm{CCC}$ greater than 0.75 in the calibration data set.

that the dye did not flow consistently between the sets of phototransistors. Velocities from measurements with low CCC values were often inaccurate. The significant outlier at the highest velocity in figure 9 is an example of a low CCC (0.65) indicating an inaccurate measurement. Using 0.75 as the threshold, accepted as good measurements were all ten measurements for velocities below $2 \mathrm{~m} \mathrm{~s}^{-1}$ and at $3.5 \mathrm{~m} \mathrm{~s}^{-1}$ for both phototransistors, all ten measurements for the $180^{\circ}$ phototransistor at $2.5 \mathrm{~m} \mathrm{~s}^{-1}$, nine out of ten measurements for the $180^{\circ}$ phototransistor at 3 and $4 \mathrm{~m} \mathrm{~s}^{-1}$ and for the $45^{\circ}$ phototransistor at 2.5 and $3 \mathrm{~m} \mathrm{~s}^{-1}$, eight out of ten measurements for the $45^{\circ}$ phototransistors at $4 \mathrm{~m} \mathrm{~s}^{-1}$, and finally seven out of ten measurements for both phototransistors at $4.5 \mathrm{~m} \mathrm{~s}^{-1}$. This ability to determine measurement quality through the use of the CCC was one of the strengths of this method.

The mean percent error (MPE) was calculated at each velocity using only measurements with $\mathrm{CCC}$ values above 0.75. Figure 11 shows the MPE for the calibration data set.

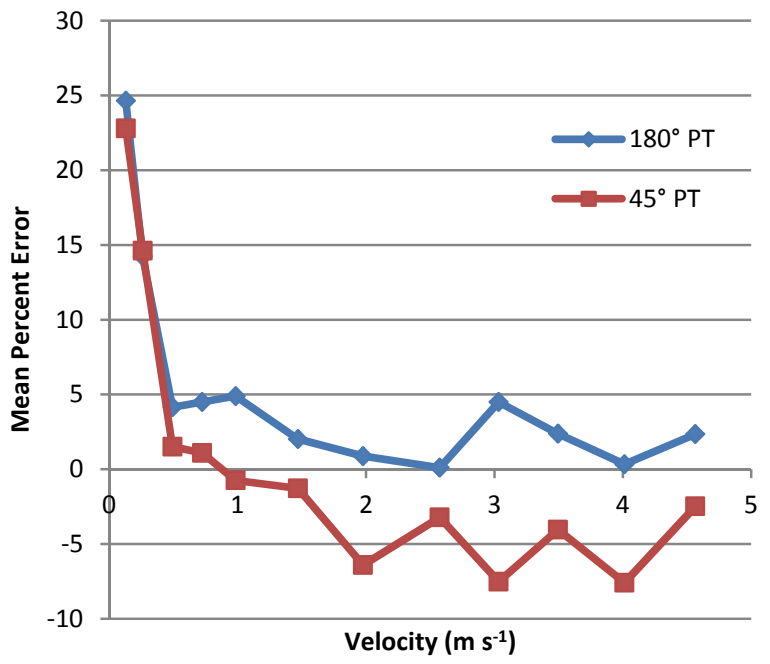

Figure 11. Mean percent error at each velocity in the calibration test. 
Table 1. Calibration equations from the regression analysis for each phototransistor $(\mathrm{PT})$ position $(\mathrm{TV}=$ true velocity, $\mathrm{MV}=$ measured velocity, and $\mathrm{CI}=$ confidence interval).

\begin{tabular}{ccccc}
\hline \multirow{2}{*}{$\begin{array}{c}\text { PT } \\
\text { Position }\end{array}$} & Calibration Equation & $\mathrm{R}^{2}$ & Slope & Intercept \\
\cline { 4 - 5 } $180^{\circ}$ & $\mathrm{TV}=0.987(\mathrm{MV})-0.021$ & 0.999 & $\begin{array}{c}0.97 \\
\text { to } 1.00\end{array}$ & $\begin{array}{c}-0.06 \\
\text { to } 0.02\end{array}$ \\
\hline $45^{\circ}$ & $\mathrm{TV}=1.061(\mathrm{MV})-0.038$ & 0.998 & $\begin{array}{c}1.03 \\
\text { to } 1.09\end{array}$ & $\begin{array}{c}-0.11 \\
\text { to } 0.03\end{array}$ \\
\hline
\end{tabular}

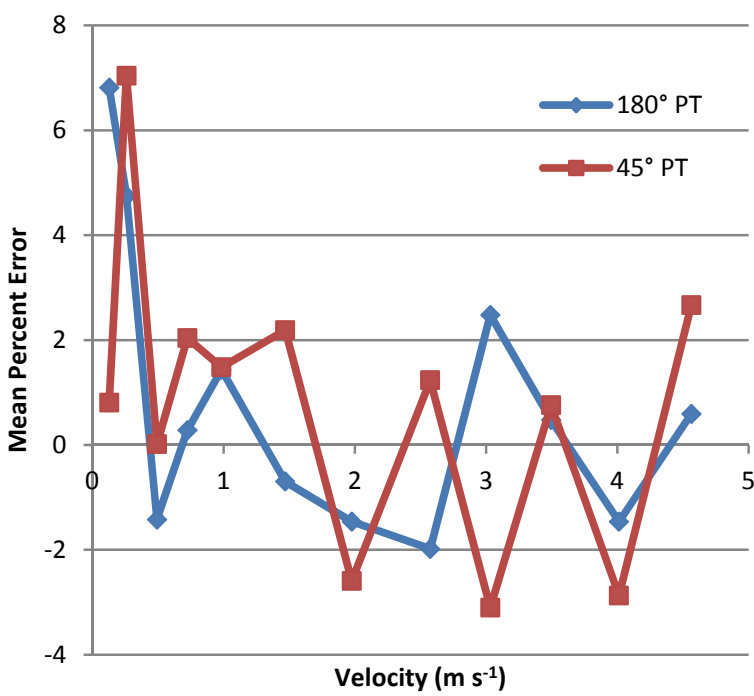

Figure 12. Mean percent error for the calibration data set after applying the regression model.

The high MPE for the measurements taken at velocities below $0.5 \mathrm{~m} \mathrm{~s}^{-1}$ indicates that the sensor significantly overestimated the velocity in this range. Above $0.5 \mathrm{~m} \mathrm{~s}^{-1}$, the measurements calculated from the $180^{\circ}$ phototransistors slightly overestimated the velocity, but by no more than $5 \%$. On the other hand, above $1 \mathrm{~m} \mathrm{~s}^{-1}$, the measurements calculated from the $45^{\circ}$ phototransistors underestimated the velocity by $3 \%$ to $8 \%$.

A linear regression analysis was performed to create a model that relates the velocity measured by the sensor to the true velocity. Separate regressions were performed for the data from the $45^{\circ}$ and $180^{\circ}$ phototransistors. The calibration equations and other results from the regression analysis are summarized in table 1. Figure 12 shows the mean percent errors when the regression model was applied to the calibration data set. The regression model significantly reduced the mean percent errors. The highest mean percent error is now $7 \%$ or less at velocities less than $0.5 \mathrm{~m}$ $\mathrm{s}^{-1}$ and between $3 \%$ and $-3 \%$ at velocities above $0.5 \mathrm{~m} \mathrm{~s}^{-1}$ for both the measurements from the $180^{\circ}$ and $45^{\circ}$ phototransistors.

\section{VALIDATION TEST}

The velocities determined by the cross-covariance calculation using the signals from the $180^{\circ}$ and $45^{\circ}$ phototransistors for the validation data set are compared to the actual velocity in figures 13 and 14, respectively. The ideal sensor response is shown as a solid line on each graph. Similar to the calibration data set, the CCC values decrease with in-

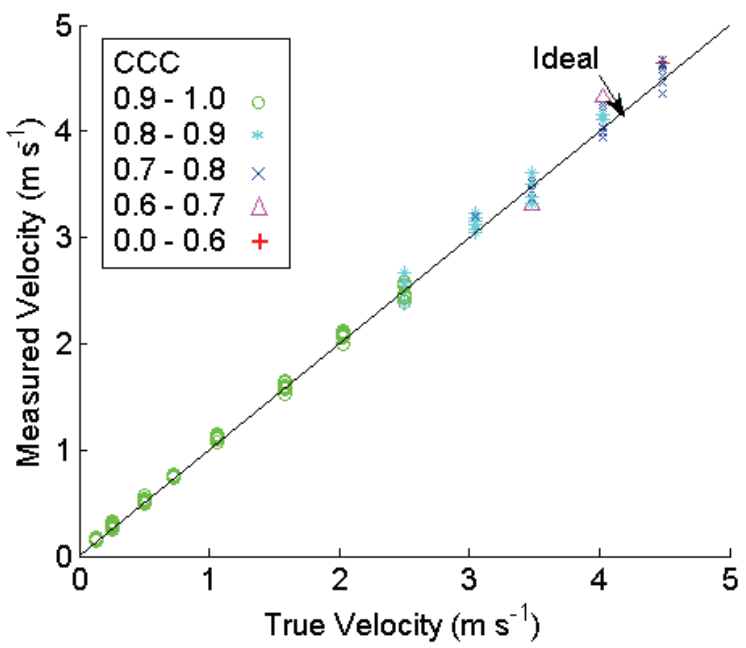

Figure 13. Measured velocity compared to true velocity and $\mathrm{CCC}$ of each measurement using the signals from the $180^{\circ}$ phototransistors in the validation test.

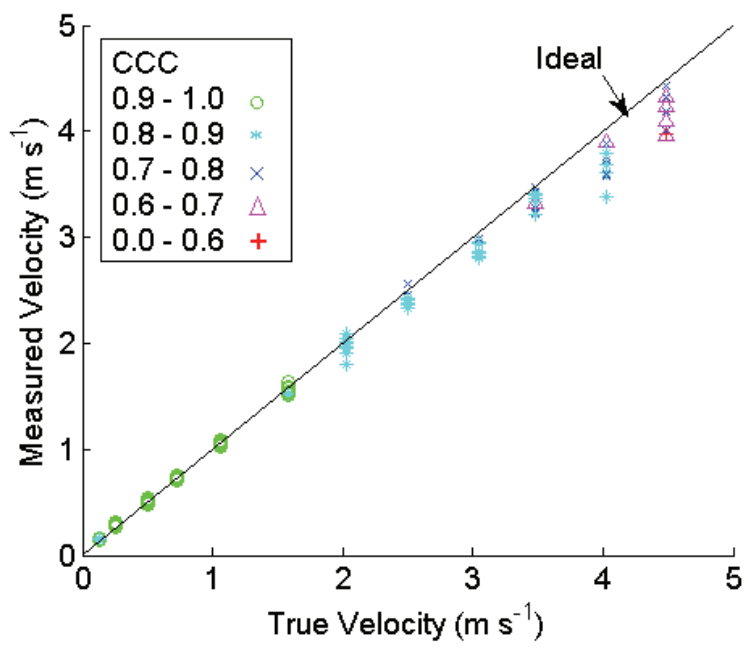

Figure 14. Measured velocity compared to true velocity and $\mathrm{CCC}$ of each measurement using the signals from the $45^{\circ}$ phototransistors in the validation test.

creasing velocity, and the measurements from the $45^{\circ}$ phototransistors generally have lower CCC values than those from the $180^{\circ}$ phototransistors.

As with the calibration data set, only measurements with CCC values above 0.75 were considered acceptable. The percentage of measurements with CCC values higher than 0.75 in the validation data set is shown in figure 15 . Using 0.75 as the threshold for CCC, all ten measurements for velocities below $2 \mathrm{~m} \mathrm{~s}^{-1}$ for both phototransistors, all ten measurements for the $180^{\circ}$ phototransistor at $2.5 \mathrm{~m} \mathrm{~s}^{-1}$, nine out of ten measurements both phototransistors at $3 \mathrm{~m} \mathrm{~s}^{-1}$ and for the $45^{\circ}$ phototransistor at $2.5 \mathrm{~m} \mathrm{~s}^{-1}$, eight out of ten measurements for both phototransistors at $4 \mathrm{~m} \mathrm{~s}^{-1}$ and for the $45^{\circ}$ phototransistor at $3.5 \mathrm{~m} \mathrm{~s}^{-1}$, six out of ten measurements for the $180^{\circ}$ phototransistor at $3.5 \mathrm{~m} \mathrm{~s}^{-1}$, and two out of ten measurements for the $180^{\circ}$ phototransistor at $4 \mathrm{~m} \mathrm{~s}^{-1}$ were accepted as good measurements. No measurements for the $45^{\circ}$ phototransistor at $4.5 \mathrm{~m} \mathrm{~s}^{-1}$ were acceptable. The graph is similar to figure 10 for the calibration data set except that, for the validation test, there were fewer accepta- 


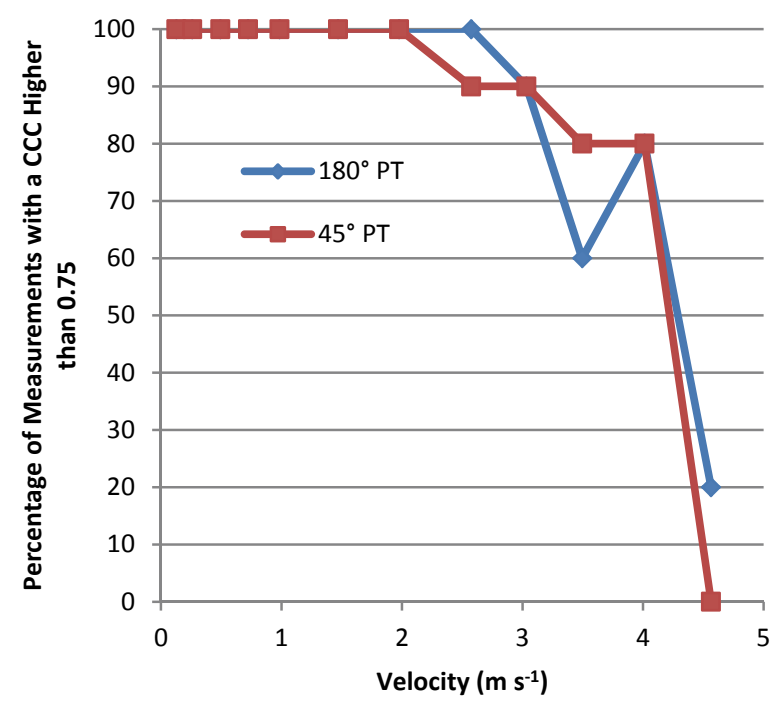

Figure 15. Percent of measurements with $\mathrm{CCC}$ values greater than 0.75 in the validation data set.

ble measurements at velocities above $3.5 \mathrm{~m} \mathrm{~s}^{-1}$.

Figure 16 is the MPE of the velocity estimates from the sensor compared to the actual velocities for the validation data set. Unlike the calibration data set, there is an increase in MPE at 1 and $1.5 \mathrm{~m} \mathrm{~s}^{-1}$. Otherwise, the velocity estimates from the validation data set follow the same trends as the calibration data set. At $0.125 \mathrm{~m} \mathrm{~s}^{-1}$, the velocity is overestimated by around $20 \%$, and then above $2 \mathrm{~m} \mathrm{~s}^{-1}$ the measurements from the $45^{\circ}$ phototransistors underestimate velocity, while those from the $180^{\circ}$ phototransistors are limited to a mean percent error of within $\pm 3 \%$.

Finally, the regression models derived from the calibration test were applied to the validation data set. The MPE after applying the regression models is shown in figure 17. At $0.125 \mathrm{~m} \mathrm{~s}^{-1}$, the regression models significantly reduced the measurement error from about $20 \%$ to $3.4 \%$ and $-3.4 \%$

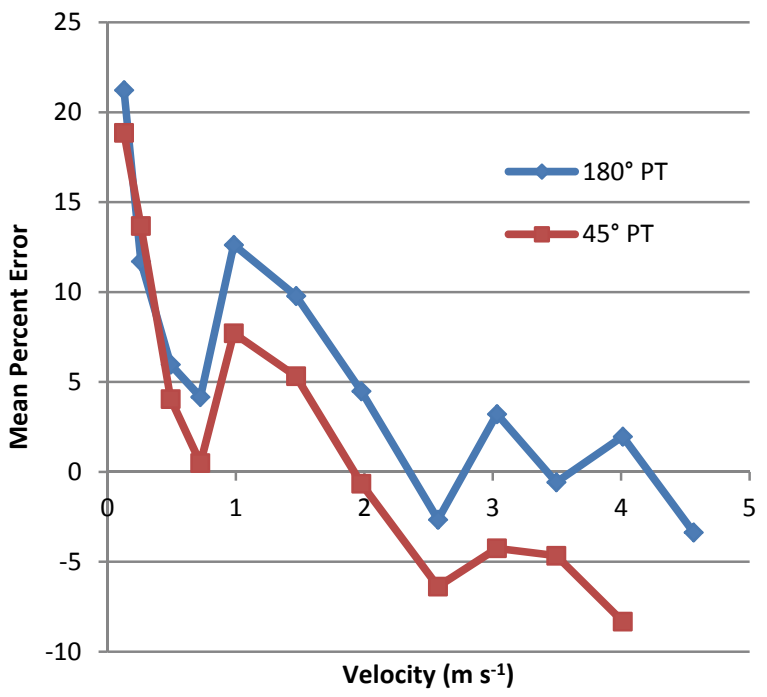

Figure 16. Mean percent error at each velocity in the validation test set (not corrected using the regression model).

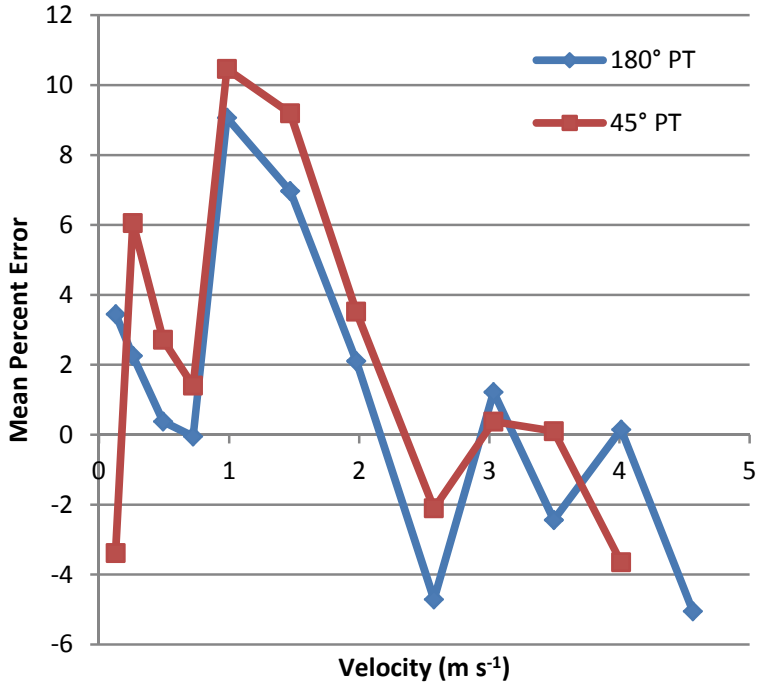

Figure 17. Mean percent error of measurements in validation data set after applying the regression model.

for the $180^{\circ}$ and $45^{\circ}$ phototransistors, respectively. The measurements from the $45^{\circ}$ phototransistors were also improved at velocities greater than $2 \mathrm{~m} \mathrm{~s}^{-1}$. Unfortunately, there is an increase in error at 1 and $1.5 \mathrm{~m} \mathrm{~s}^{-1}$ for the measurements from both sets of phototransistors. For all other velocities, the regression model restricted the measurement error within $\pm 5 \%$ using both the $180^{\circ}$ and $45^{\circ}$ phototransistors.

The improvement in results after applying the regression model demonstrates that the model was necessary. The sensor operated by detecting the time delay of the effect of dye at different locations. However, the movement of dye did not always perfectly match the average velocity of the water, especially at velocities below $0.5 \mathrm{~m} \mathrm{~s}^{-1}$. A possible contributing factor for this discrepancy could be diffusion of the dye after it is injected into the water. In order to examine this possibility, a simple test was conducted. In this test, a drop of dye was injected into a pipe similar to that used in the test setup and filled with still water. The dye drop expanded by diffusion, and the edge of the drop moved in the radial direction at a rate of $0.38 \mathrm{~mm} \mathrm{~s}^{-1}$, which was well below the measured water velocity range $\left(0.125\right.$ to $\left.4.5 \mathrm{~m} \mathrm{~s}^{-1}\right)$. Thus, it can be concluded that the diffusion of the dye drop in water alone cannot account for the measurement error. Another possible explanation for the difference at velocities below 0.5 $\mathrm{m} \mathrm{s}^{-1}$ was that the flow was transitioning from turbulent to transitional to nearly laminar flow in this region, which could affect how the dye is carried by the flow. Under fully turbulent conditions, the maximum velocity in the cross-sectional velocity profile within a pipe is close to the average velocity. For laminar flows, the velocity profile is parabolic, with an average velocity much lower than the maximum velocity. Because the region within the pipe through which the dye travels is unknown, this parabolic velocity profile could easily cause discrepancies between the measured and average velocities. In fluid mechanics, the average-to-maximum velocity ratio was predicted to be 0.5 in laminar flow, 0.794 at a Reynolds number of 4,000, and 0.814 at a Reynolds number 
of 10,000. These are similar to the Reynolds numbers of the flows tested at $0.125,0.25$, and $0.5 \mathrm{~m} \mathrm{~s}^{-1}$, which had Reynolds numbers of 2,383 (nearly laminar), 4,765, and 9,530, respectively. However, the measurement errors at these velocities were not nearly as high as what can be explained by the average-to-maximum velocity ratios, indicating that the dye traveled in the fluid at a velocity that was closer to the average velocity. To correct for the measurement error, a regression model was created through calibration.

Although this article only reports the tests of the sensor in enclosed-flow situations, the intended applications of the sensor include open-channel flow measurement for water monitoring. Therefore, it is useful to compare its abilities with other commonly used sensors that are capable of open-channel applications. The accuracy of the sensor in velocity measurement is lower than some commercially available velocity measurement devices. For example, Camnasio and Orsi (2011) reported being able to calibrate the traditional propeller or cup based meters used in openchannel flows with uncertainty on the order of $\pm 1 \%$ to $2 \%$. SonTek/YSI (2013) advertises that its acoustic Doppler velocimeter, the FlowTracker Handheld-ADV, has an accuracy of $\pm 1 \%$ of measured velocity or $\pm 0.25 \mathrm{~cm} \mathrm{~s}^{-1}$. However, these sensors are expensive and are not robust enough to allow long-term field installation without significant effort to protect the device. The sensor discussed in this article is comprised of low-cost components, and the body of the sensor is easily manufactured, making it much more suitable for long-term field installation.

\section{Conclusion}

We tested a correlation-based optical sensor in measuring velocity of enclosed water flows in the range of 0.125 to $4.5 \mathrm{~m} \mathrm{~s}^{-1}$ under controlled experimental conditions in the laboratory. The cross-correlation coefficients of measurements were highest at low velocities and decreased as velocity increased. In addition, the measurements made with the $180^{\circ}$ phototransistors had higher cross-correlation coefficients at a given velocity than those made with the $45^{\circ}$ phototransistors. In the test using the calibration data set, measurements made with the $180^{\circ}$ phototransistors had a mean percent error of between $0 \%$ and $5 \%$ from 0.5 to $4.5 \mathrm{~m} \mathrm{~s}^{-1}$. However, at velocities below $0.5 \mathrm{~m} \mathrm{~s}^{-1}$, the mean percent error increased and reached nearly $25 \%$ at $0.125 \mathrm{~m}$ $\mathrm{s}^{-1}$. A similar trend was observed in the measurements performed using the $45^{\circ}$ phototransistors, but in addition to overestimating low velocities, these measurements also underestimated velocities above $2 \mathrm{~m} \mathrm{~s}^{-1}$. A linear regression model based on the calibration data set was established to correct the velocity measurements for each set of phototransistors. When these models were applied to the validation data set, the maximum percent error decreased from about $20 \%$ to less than $11 \%$. Thus, the correction model significantly improved the accuracy of the sensor.

\section{ACKNOWLEDGEMENTS}

The authors would like to thank the Environmental Security Technology Certification Program (ESTCP) for funding this research. The NSF GK-12 Program is also acknowledged for providing a fellowship for one of the authors during this study.

\section{REFERENCES}

Adrian, R. J. 1983. Laser velocimetry. In Fluid Mechanics: Measurement, 155-244. Washington, D.C.: Hemisphere Publishing.

ASHRAE. 2009. 2009 ASHRAE Handbook - Fundamentals (SI Edition). Atlanta, Ga.: ASHRAE, Inc.

Bendat, J. S., and A. G. Piersol. 1986. Random Data. New York, N.Y.: John Wiley and Sons.

Bendat, J. S., and A. G. Piersol. 1993. Engineering Applications of Correlation and Spectral Analysis. New York, N.Y.: John Wiley and Sons.

Blake, W. K. 1983. Differential pressure measurement. In Fluid Mechanics: Measurement, 61-97. Washington, D.C.: Hemisphere Publishing.

Bundt, M., F. Widmer, M. Pesaro, J. Zeyer, and P. Blaser. 2001. Preferential flow paths: Biological 'hot spots' in soils. Soil Biol. and Biochem. 33(6): 729-738.

Camnasio, E., and E. Orsi. 2011. Calibration method of current meters. J. Hydraul. Eng. 137(3): 386-397.

Chang, C. S., C. R. Martin, and F. S. Lai. 1986. Grain velocity measurement with optical sensors. Trans. ASAE 29(5): 14511455.

Dodge, R. 2001. Water Measurement Manual: A Guide to Effective Water Measurement Practices for Better Water Management. Washington, D.C.: Department of the Interior, Bureau of Reclamation.

Eamopas, K., N. Zhang, and M. Schrock. 1994. Monitoring the glass bead dispensing rate for highway striping vehicles. ITE $J$. 64(4): 41-46.

Eam-o-pas, K., N. Zhang, and M. D. Schrock. 1997. Parameter selection for correlation-based particle velocity sensors. Trans. ASAE 40(5): 1501-1508.

Elsinga, G. E., F. Scarano, B. Wieneke, and B. W. van Oudheusden. 2006. Tomographic particle image velocimetry. Exp. Fluids 41(6): 933-947.

Flury, M., and H. Flühler. 1994. Brilliant blue FCF as a dye tracer for solute transport studies: A toxicological overview. $J$. Environ. Qual. 23(5): 1108-1112.

Flury, M., and H. Flühler. 1995. Tracer characteristics of brilliant blue FCF. SSSA J. 59(1): 22-27.

Jenkins, G. M., and D. G. Watts. 1968. Spectral Analysis and its Applications. San Francisco, Cal.: Holden-Day.

Levesque, V. A., and K. A. Oberg. 2012. Computing discharge using the index velocity method. Reston, Va.: U.S. Geological Survey.

Motz, E., E. Cey, M. C. Ryan, and A. Chu. 2012. Vadose zone microbial transport below at-grade distribution of wastewater effluent. Water Air and Soil Poll. 223(2): 771-785.

Muste, M., T. Vermeyen, R. Hotchkiss, and K. Oberg. 2007. Acoustic velocimetry for riverine environments. J. Hydraul. Eng. 133(12): 1297-1298.

Raffel, M., C. E. Willert, S. T. Wereley, and J. Kompenhans. 2007. Particle Image Velocimetry: A Practical Guide. New York, N.Y.: Springer.

Shercliff, J. A. 1962. The Theory of Electromagnetic Flow Measurement. Cambridge, U.K.: Cambridge University Press.

SonTek/YSI. 2013. FlowTracker Handheld ADV brochure. San Diego, Cal.: SonTek/YSI. Available at: www.sontek.com/pdf/ brochures/flowtracker_S01-05-0411.pdf.

Stoll, Q. 2004. Design of a real-time, optical sediment concentration sensor. Manhattan, Kans.: Kansas State University, Department 
of Biological and Agricultural Engineering.

Upp, E. L., and P. J. LaNasa. 2002. Fluid Flow Measurement: A Practical Guide to Accurate Flow Measurement. Woburn, Mass.: Butterworth-Heinemann.

Vondricka, J., and P. S. Lammers. 2009. Measurement of mixture homogeneity in direct injection systems. Trans. ASABE 52(1): 61-66.

Vryzas, Z., E. N. Papadakis, and E. Papadopoulou-Mourkidou. 2012. Leaching of Br-, metolachlor, alachlor, atrazine, deethylatrazine, and deisopropylatrazine in clayey vadose zone: A field-scale experiment in north-east Greece. Water Research 46(6): 1979-1989.

White, F. M. 2003. Fluid Mechanics. New York, N.Y.: McGrawHill Higher Education.

Zhang, Y. 2009. An optical sensor for in-stream monitoring of suspended sediment concentration. Manhattan, Kans.: Kansas State University, Department of Biological and Agricultural Engineering. 